\title{
Investigation of the Effects of Submerged Arc Welding Process Parameters on the Mechanical Properties of Pressure Vessel Steel ASTM A283 Grade A
}

\author{
Prachya Peasura \\ Welding Technology Laboratory, Department of Production Technology Education, Faculty of Industrial Education and Technology, \\ King Mongkut's University of Technology Thonburi (KMUTT), Bangkok 10140, Thailand \\ Correspondence should be addressed to Prachya Peasura; prachya.pea@kmutt.ac.th
}

Received 16 October 2016; Revised 18 December 2016; Accepted 28 December 2016; Published 5 February 2017

Academic Editor: Sheng-Rui Jian

Copyright (C) 2017 Prachya Peasura. This is an open access article distributed under the Creative Commons Attribution License, which permits unrestricted use, distribution, and reproduction in any medium, provided the original work is properly cited.

\begin{abstract}
The pressure vessel steel is used in boilers and pressure vessel structure applications. This research studied the effects of submerged arc welding (SAW) process parameters on the mechanical properties of this steel. The weld sample originated from ASTM A283 grade A sheet of 6.00-millimeter thickness. The welding sample was treated using SAW with the variation of three process factors. For the first factor, welding currents of 260, 270, and 280 amperes were investigated. The second factor assessed the travel speed, which was tested at both 10 and 11 millimeters/second. The third factor examined the voltage parameter, which was varied between 28 and 33 volts. Each welding condition was conducted randomly, and each condition was tested a total of three times, using full factorial design. The resulting materials were examined using tensile strength and hardness tests and were observed with optical microscopy $(\mathrm{OM})$ and scanning electron microscopy (SEM). The results showed that the welding current, voltage, and travel speed significantly affected the tensile strength and hardness $(P$ value $<0.05)$. The optimum SAW parameters were 270 amperes, 33 volts, and 10 millimeters/second travel speed. High density and fine pearlite were discovered and resulted in increased material tensile strength and hardness.
\end{abstract}

\section{Introduction}

ASTM A283 grade A steel is a boiler pressure vessel quality steel that has good weldability and excellent notch toughness. It is perfect for moderate and lower temperature applications. This material is used extensively by boiler and pressure vessel fabricators that provide manufacturing support to the petrochemical, oil, and gas industries. Steels containing anywhere from $0.15 \%$ to $0.30 \%$ carbon are commonly known as mild steel. Underbead cracking or a lack of toughness in the heat-affected zone is not usually encountered when welding carbon steel containing no more than $0.2 \%$ carbon and $1 \%$ manganese. Such steel can be welded without preheating, post weld heat treatment, or special welding procedures when the joint thickness is less than 1 inch, and joint restrain is not severe. Pressure vessel ASTM A283 grade A steel, which is used in both pressure vessels and industrial boilers, is an excellent choice for service in lower than ambient temperature applications and has excellent notch toughness $[1,2]$.

Welding parameters such as current, voltage, wire feed rate, and electrode extension length are the principal parameters of submerged arc welding (SAW). The voltage or the arc length determines the arc force. A short arc focuses the available force on a small area of the weld pool, thus giving deeper penetration and narrower welds. The wire feed rate is also a contributing factor in determining penetration and weld shape. The electrode feed rate is adjusted to obtain the desired voltage for good fusion and penetration [3]. Li et al. [4] experimented with a new method of applying a direct current external circuit in submerged arc welding processes between the slag and weld pool to control inclusions and improve weld metal appearance.

Full factorial design is particularly useful in the stages of experimental work. A factorial design is often used to study the effects of two or more independent variables upon 
TABLE 1: Chemical composition of ASTM A283 grade A steel by weight (\%).

\begin{tabular}{lccccccccc}
\hline $\mathrm{C}$ & $\mathrm{Mn}$ & $\mathrm{Si}$ & $\mathrm{Cu}$ & $\mathrm{Cr}$ & $\mathrm{P}$ & $\mathrm{S}$ & $\mathrm{Mo}$ & $\mathrm{Ni}$ & $\mathrm{Al}$ \\
\hline 0.142 & 0.424 & 0.015 & 0.037 & 0.025 & 0.010 & 0.010 & 0.010 & 0.021 & 0.040 \\
\hline
\end{tabular}

TABLE 2: The experimental factors of the full factorial design.

\begin{tabular}{lcccc}
\hline Factors & Units & \multicolumn{3}{c}{ Levels } \\
\hline Welding current & Amp & 260 & 270 & 280 \\
Voltage & $\mathrm{V}$ & 28 & 33 & - \\
Travel speed & $\mathrm{mm} / \mathrm{sec}$ & 10 & 11 & - \\
\hline
\end{tabular}

a single dependent variable [5]. Mohsen et al. [6] applied a $2^{3}$ factorial design to study the effects of shield metal arc welding on cast iron steel. The research focused on the three factors of the electrode as well as preheating and cooling conditions. Jafari et al. [7] tested a $3^{4}$ full factorial design to identify the significant manufacturing parameters that affect the properties of lost foam casting of an $\mathrm{Al}-\mathrm{Si}-\mathrm{Cu}$ cast alloy.

This work focuses on the effects of SAW parameters on the mechanical properties of pressure vessel ASTM A283 grade A steel. Optimum values for the factors in the SAW process were determined using a full factorial experimental design. This research can assist in choosing the appropriate SAW parameters for welding pressure vessel ASTM A283 grade A steel.

\section{Research Methodology}

2.1. Materials and Methods. The pressure vessel ASTM A283 grade A steel plate was $6.00 \mathrm{~mm}$ thick. The detailed material chemical composition is given in Table 1 .

The welding samples were SAW welded with pressure vessel ASTM A283 grade A steel, using welding currents of 260,270 , and 280 amperes. The welding voltages were set to 28 or 33 volts. The welding speeds were maintained at either 10 or $11 \mathrm{~mm} / \mathrm{sec}$, and the electrode (LC-72) diameter was $2.00 \mathrm{~mm}$.

After welding, the specimens were mechanically tested. Welded samples were sectioned transversely to the weld and polished using standard metallographic techniques. The weld specimens were examined and analyzed by the inverted tensile strength test following ASTM standard. The microhardness was determined using a 1,000 g load to observe the effects of the SAW factors in the heat-affected zone $[8,9]$. The SAW weld samples polished for optical microscopy (OM) and scanning electron microscopy (SEM) investigations were etched with $\mathrm{HNO}_{3}(2 \mathrm{ml})$ and methanol $(98 \mathrm{ml})$ [9].

2.2. Experimental Design. The experiments were designed to determine the optimal welding conditions. A full factorial experimental design was used to study the main effects and influences of the factors that affect the tensile strength and hardness. The welding factors examined in this study included welding current, voltage, and travel speed as shown in Tables 2 and 3:
Hypotheses of the experiment (with $95 \%$ confidence $(P$ value $<0.05))$

$H_{0} ;(\tau \beta)_{i j}=0$ indicates that welding factors do not affect tensile strength and hardness

$H_{1} ;(\tau \beta)_{i j} \neq 0$ indicates that welding factors and time affect tensile strength and hardness

\section{Results and Discussion}

3.1. Tensile Strength. Analysis of variance results and conclusions of the trial analyzing the variability in the full factorial experimental design are shown in Table 4.

The effects of the SAW process parameters on the tensile strength were determined at a confidence level of 95\% ( $P$ value $<0.05)[10]$. The results indicate that the data could be predicted using the model. $R_{\text {adj }}^{2}$ of the collected data was approximately $92.59 \%$, which shows that the response can be described by the experimental factors shown in Table 4 .

Figure 1 shows the distribution of the residuals in the normal distribution for tensile strength analysis. The normal distribution was used to test the residual distribution. The results show that the residuals were distributed along a straight line from the middle of the histogram. The residual value of the distribution was a normal shape, and the residuals were estimated to have a normal distribution.

Figure 2 shows the effects of the welding parameters on the tensile strength. An interaction between these variables is apparent when the lines in the plot were not parallel. The results show that the highest tensile strength achieved was $541 \mathrm{MPa}$ for a welding current of 270 amperes, voltage of 33 volts, and travel speed of $10 \mathrm{~mm} / \mathrm{sec}$.

3.2. Hardness Analysis. From the ANOVA test listed in Table 5, data analysis showed hardness terms of $R^{2}=$ $93.71 \%$ and $R_{\text {adj }}^{2}=90.83 \%$, and thus the decision satisfies coefficients of $P$ value of ANOVA, which is $0.000<\alpha$, and we reject the null hypothesis. The result showed that two of the SAW factors affected hardness at the $95 \%$ confidence level.

Figure 3 shows the residual plot for hardness. The statistical data analysis was performed and validated by experimental models. The hypothesis was that the pattern of the residuals obtained from the experimental data adheres to the principle $\varepsilon_{i j} \sim \operatorname{NID}\left(0, \sigma^{2}\right)$ [11]. Residuals were assumed to be independent and normally distributed. The mean 0 and $\sigma^{2}$ are stable in the experimental data. The results showed that the data are random, thus concluding the experimental results for hardness.

Figure 4 shows the effects of the SAW factors on the hardness. An interaction between these factors is apparent when the lines in the plot are not parallel. The line plot indicates that there were strong interactions between the welding factors and the hardness. The results show that the highest hardness achieved during the SAW factors was $254 \mathrm{HV}$ at a current of 270 amperes, voltage of 33 volts, and travel speed of $10 \mathrm{~mm} / \mathrm{sec}$.

3.3. Microstructure Observations. As observed in the heataffected zone (HAZ), the microstructure at the weld material 
TABLE 3: Matrix of the welding and response factors for hardness and tensile strength.

\begin{tabular}{|c|c|c|c|c|c|c|}
\hline Std. order & Run order & Current & Voltage & Travel speed & Hardness (HV) & Tensile strength $(\mathrm{MPa})$ \\
\hline 1 & 22 & 260 & 28 & 10 & 246.47 & 527.5 \\
\hline 2 & 3 & 260 & 28 & 10 & 244.21 & 530.2 \\
\hline 3 & 31 & 260 & 28 & 10 & 247.60 & 534.5 \\
\hline 4 & 19 & 260 & 28 & 11 & 241.57 & 521.2 \\
\hline 5 & 1 & 260 & 28 & 11 & 247.30 & 523.8 \\
\hline 6 & 13 & 260 & 28 & 11 & 243.07 & 528.5 \\
\hline 7 & 30 & 270 & 28 & 10 & 259.67 & 534.3 \\
\hline 8 & 6 & 270 & 28 & 10 & 254.67 & 539.2 \\
\hline 9 & 33 & 270 & 28 & 10 & 261.47 & 533.5 \\
\hline 10 & 2 & 270 & 28 & 11 & 236.87 & 519.4 \\
\hline 11 & 20 & 270 & 28 & 11 & 234.37 & 522.3 \\
\hline 12 & 23 & 270 & 28 & 11 & 239.17 & 516.4 \\
\hline 13 & 32 & 280 & 28 & 10 & 257.57 & 513.4 \\
\hline 14 & 10 & 280 & 28 & 10 & 252.77 & 515.6 \\
\hline 15 & 14 & 280 & 28 & 10 & 258.03 & 512.2 \\
\hline 16 & 29 & 280 & 28 & 11 & 224.07 & 514.4 \\
\hline 17 & 5 & 280 & 28 & 11 & 227.80 & 509.6 \\
\hline 18 & 34 & 280 & 28 & 11 & 229.03 & 510.2 \\
\hline 19 & 11 & 260 & 33 & 10 & 235.75 & 528.2 \\
\hline 20 & 18 & 260 & 33 & 10 & 232.37 & 523.1 \\
\hline 21 & 15 & 260 & 33 & 10 & 238.03 & 528.4 \\
\hline 22 & 26 & 260 & 33 & 11 & 234.43 & 513.8 \\
\hline 23 & 35 & 260 & 33 & 11 & 239.37 & 519.8 \\
\hline 24 & 4 & 260 & 33 & 11 & 235.67 & 514.2 \\
\hline 25 & 21 & 270 & 33 & 10 & 255.07 & 543.1 \\
\hline 26 & 28 & 270 & 33 & 10 & 250.57 & 538.2 \\
\hline 27 & 9 & 270 & 33 & 10 & 257.87 & 542.0 \\
\hline 28 & 25 & 270 & 33 & 11 & 250.17 & 521.1 \\
\hline 29 & 17 & 270 & 33 & 11 & 253.97 & 525.3 \\
\hline 30 & 36 & 270 & 33 & 11 & 249.53 & 520.9 \\
\hline 31 & 7 & 280 & 33 & 10 & 252.87 & 527.4 \\
\hline 32 & 24 & 280 & 33 & 10 & 247.10 & 528.2 \\
\hline 33 & 16 & 280 & 33 & 10 & 255.60 & 526.1 \\
\hline 34 & 27 & 280 & 33 & 11 & 250.27 & 544.7 \\
\hline 35 & 8 & 280 & 33 & 11 & 246.17 & 540.9 \\
\hline 36 & 12 & 280 & 33 & 11 & 251.87 & 546.1 \\
\hline
\end{tabular}

TABLE 4: Analysis of variance for tensile strength.

\begin{tabular}{|c|c|c|c|c|c|c|}
\hline Source & DF & Seq SS & Adj SS & Adj MS & $F$ & $P$ \\
\hline Current & 2 & 233.37 & 233.37 & 116.68 & 14.64 & 0.000 \\
\hline Voltage & 1 & 436.11 & 436.11 & 436.11 & 54.73 & 0.000 \\
\hline Travel speed & 1 & 351.56 & 351.56 & 351.56 & 44.12 & 0.000 \\
\hline Current $*$ voltage & 2 & 1326.68 & 1326.68 & 663.34 & 83.25 & 0.000 \\
\hline Current $*$ travel speed & 2 & 932.89 & 932.89 & 466.44 & 58.54 & 0.000 \\
\hline Voltage $*$ travel speed & 1 & 37.41 & 37.41 & 37.41 & 4.70 & 0.040 \\
\hline Current $*$ voltage $*$ travel speed & 2 & 252.06 & 252.06 & 126.03 & 15.82 & 0.000 \\
\hline Error & 24 & 191.23 & 191.23 & 7.97 & & \\
\hline Total & 35 & 3761.31 & & & & \\
\hline$S=2.82277$ & \multicolumn{2}{|c|}{$R^{2}=94.92 \%$} & & \multicolumn{3}{|c|}{$R_{(\text {adj })}^{2}=92.59 \%$} \\
\hline
\end{tabular}


TABLE 5: Analysis of variance for hardness.

\begin{tabular}{|c|c|c|c|c|c|c|}
\hline Source & DF & Seq SS & Adj SS & Adj MS & $F$ & $P$ \\
\hline Current & 2 & 579.89 & 579.89 & 289.95 & 32.62 & 0.000 \\
\hline Voltage & 1 & 26.64 & 26.64 & 26.64 & 3.00 & 0.096 \\
\hline Travel speed & 1 & 831.27 & 831.27 & 831.27 & 93.52 & 0.000 \\
\hline Current $*$ voltage & 2 & 550.19 & 550.19 & 275.09 & 30.95 & 0.000 \\
\hline Current $*$ travel speed & 2 & 389.06 & 389.06 & 194.53 & 21.89 & 0.000 \\
\hline Voltage $*$ travel speed & 1 & 587.50 & 587.50 & 587.50 & 66.10 & 0.000 \\
\hline Current $*$ voltage $*$ travel speed & 2 & 213.66 & 213.66 & 106.83 & 12.02 & 0.000 \\
\hline Error & 24 & 213.32 & 213.32 & 8.89 & & \\
\hline Total & 35 & 3391.52 & & & & \\
\hline$S=2.98130$ & \multicolumn{2}{|c|}{$R^{2}=93.71 \%$} & & \multicolumn{3}{|c|}{$R_{(\text {adj })}^{2}=90.83 \%$} \\
\hline
\end{tabular}

Residual Plots for ultimate tensile strength
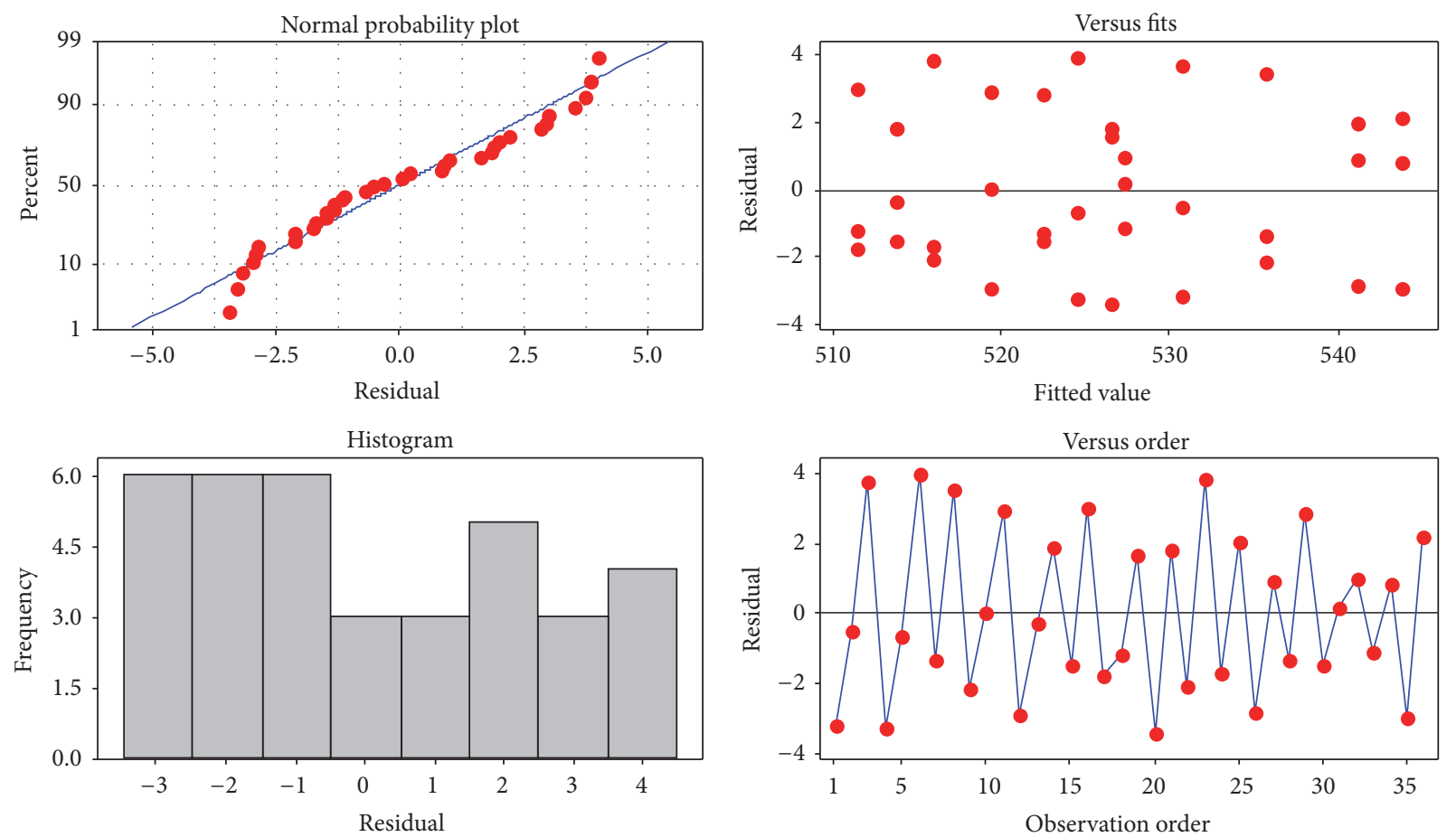

FIGURE 1: Residual plot of tensile strength.

is ferrite in the parent and pearlite phases from the gas metal arc welding [12].

Figure 5 depicts a comparison of the microstructures of the ASTM A283 grade A steel weld specimen before and after SAW welding. Figure 5(a) shows the microstructure for the original specimen, which shows the microstructure was ferrite in the parent and pearlite phases (black) $[13,14]$, and the pearlite phase had a density of $24.36 \%$ and distribution in the parent phase. The initial hardness of the original material was $175 \mathrm{HV}$. Figure 5(b) shows that the pearlite phase increased into a grain of the ferrite phase matrix, which had a pearlite phase density of $55.12 \%$, after SAM welding. The hardness of the welding specimen is $254 \mathrm{HV}$ in the HAZ. A comparison of the microstructures of the original and the welded specimens revealed clear differences. There was an increase in density of the large and lamellar pearlite, which resulted in increased material hardness and tensile strength, which can affect the hardness in the HAZ [15]. Therefore, the factors used in selecting appropriate welding also affect the microstructure and mechanical properties of welded materials.

The SEM micrograph in Figure 6 compares the density of pearlite in the specimens. Figure 6(a) also shows the microstructure for the specimen welded at a current of 280 amperes, voltage of 28 volts, and a travel speed of $11 \mathrm{~mm} / \mathrm{sec}$. It shows a decrease in the density of the pearlite phase with a predominantly coarse pearlite $[16,17]$, which is caused by the insufficient welding current voltage and travel speed. In this case, pearlite formed and contributed to the lower hardness and tensile strength [18] of $226.96 \mathrm{HV}$ and 


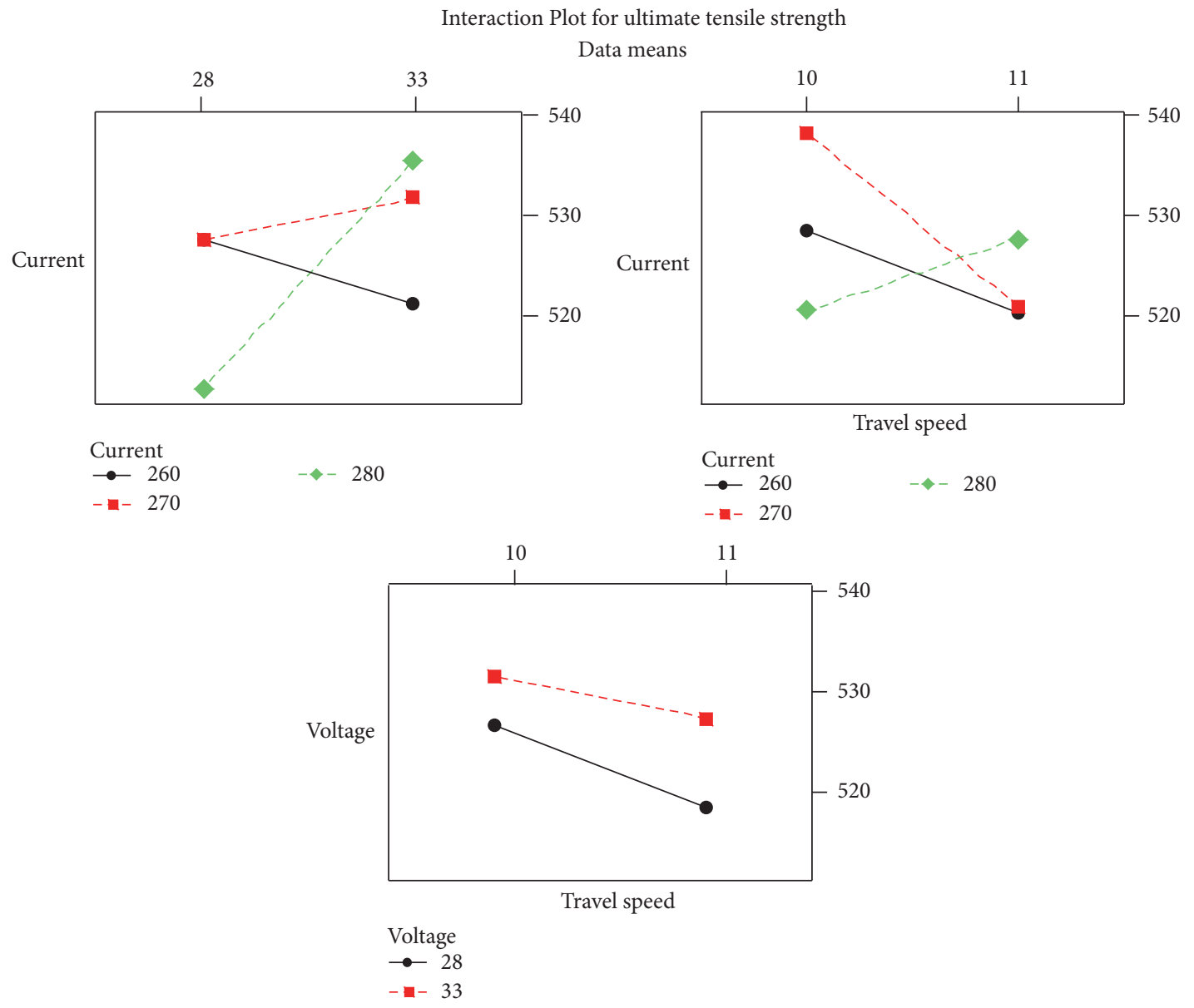

FIGURE 2: Interaction plot of tensile strength.

511.4 MPa, respectively. Figure 6(b) shows a sample welded at a current of 270 amperes, voltage of 33 volts, and a travel speed of $10 \mathrm{~mm} / \mathrm{sec}$, which also shows the microstructure for the specimen with its parent phase in ferrite and pearlite and an increase in density of the pearlite and fine pearlite causing maximum tensile strength and hardness. It was also found that suitable SAW factors improved both tensile strength and hardness properties, which affect the pearlite density in the ferrite phase shown in Figure 6. Oyyaravelu et al. [19] reported that the highest hardness and tensile strength clearly prompted the formation of martensite and pearlite phases in the weld metal and heat-affected zone. Related observations have been made by Lah et al. [20], where the highest mechanical properties of pressure vessel steel weld were a result of pearlite density and fine pearlite phase.

\section{Conclusion}

In this research, the influence of the SAW factors on the mechanical properties of ASTM A283 grade A steel was studied. The specimens were welded with welding currents of 260,270 , and 280 amperes, voltages of 28 and 33 volts, and travel speeds maintained at 10 or $11 \mathrm{~mm} / \mathrm{sec}$. The mechanical properties and microstructure were analyzed. The results from this study are summarized as follows:

(1) The factorial design of welding current with voltage and travel speed resulted in interactions on tensile strength and hardness at the $95 \%$ the confidence level $(P$ value $<0.05)$.

(2) The optimal SAW factors were a current of 270 amperes, voltage of 33 volts, and travel speed of $10 \mathrm{~mm} / \mathrm{sec}$, which resulted in tensile strength of $541 \mathrm{MPa}$ and hardness of $254 \mathrm{HV}$.

(3) The microstructure of ASTM A516 grade A steel had pearlite and ferrite when the SAW factors were optimized, which affects the pearlite density in the parent phase.

(4) The tensile strength and hardness obtained for the weld samples were found to correspond to the formation of pearlite density and fine pearlite in the weld metal and heat-affected zone.

\section{Competing Interests}

The authors declare that there are no competing interests. 
Residual plots for hardness
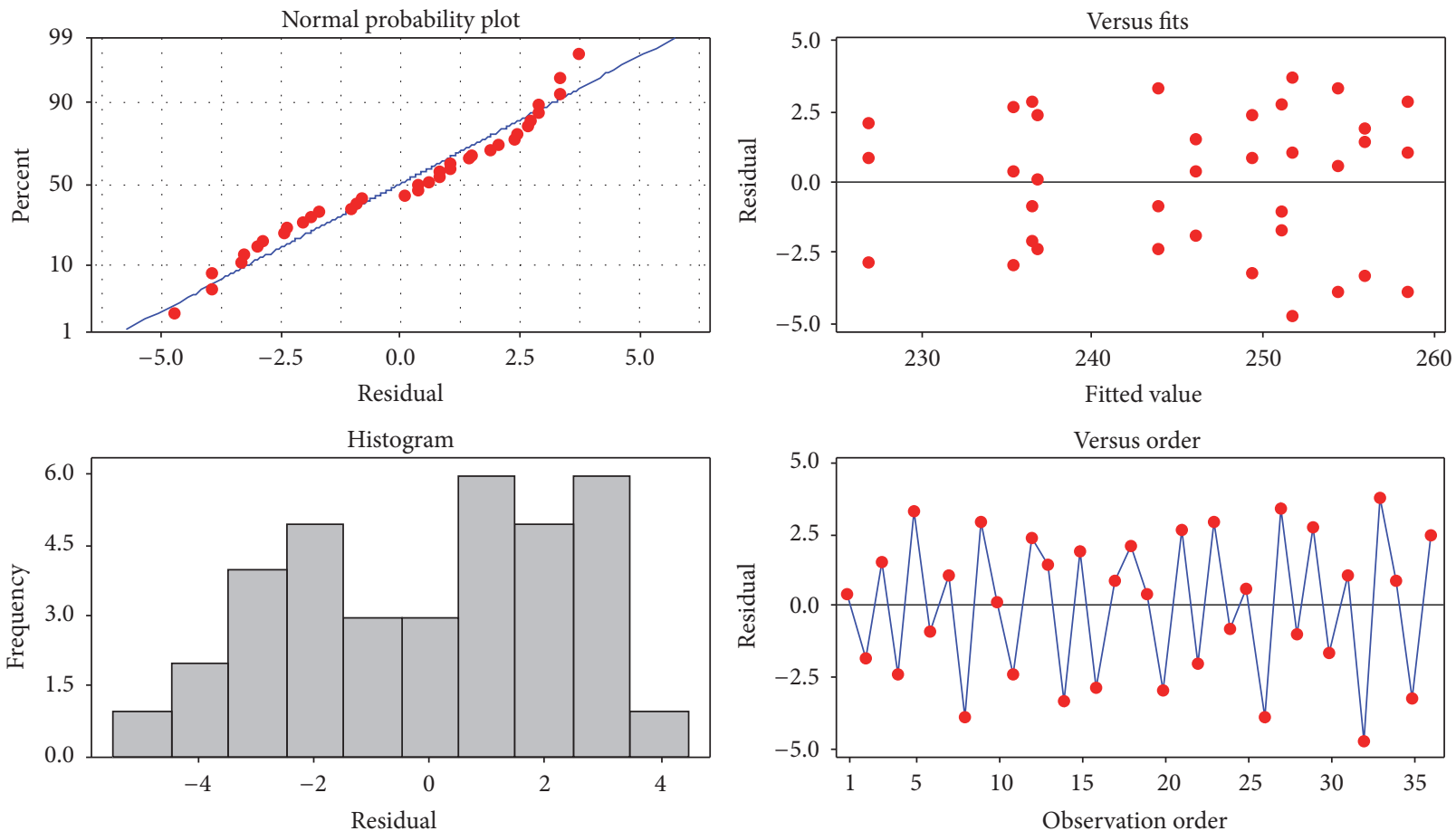

Figure 3: Residual plot of hardness.
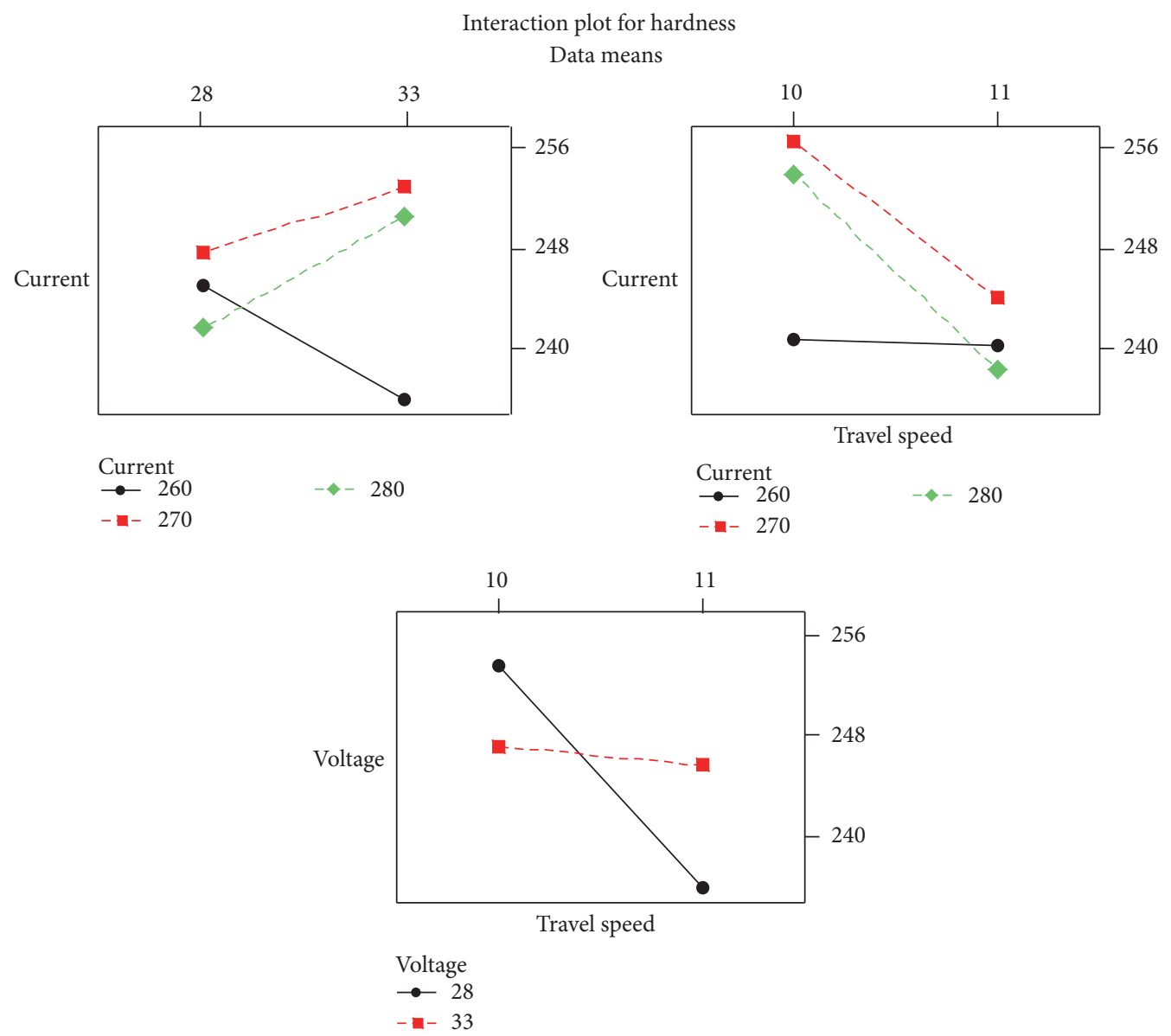

FIGURE 4: Interaction plot of hardness. 


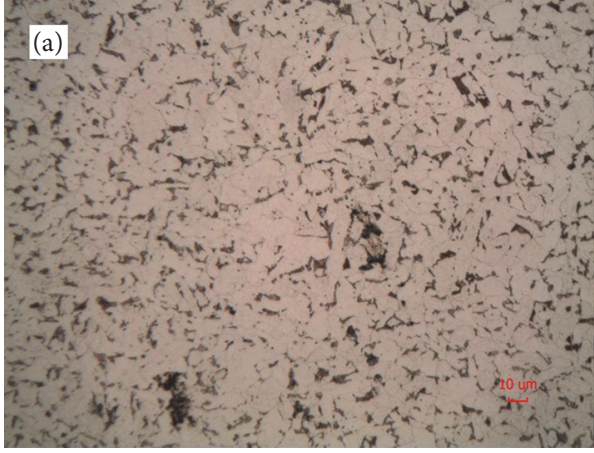

(a)



(b)

FIgURE 5: ASTM A283 grade A steel microstructure in the HAZ. (a) Original material. (b) Material after welding with the following parameters: current of 270 amperes, voltage of 33 volts, and travel speed of $10 \mathrm{~mm} / \mathrm{sec}$.

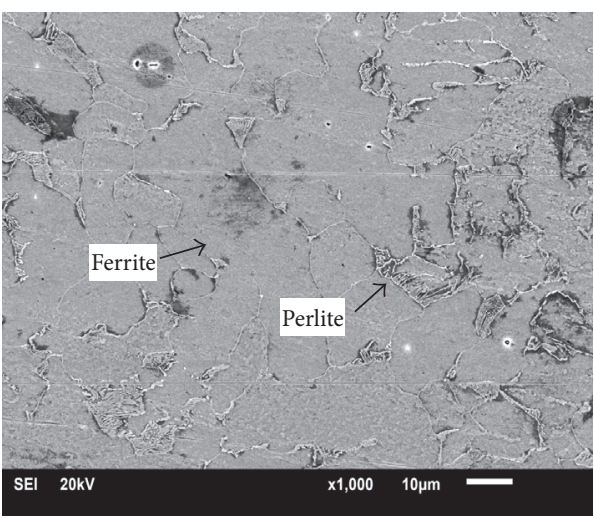

(a)

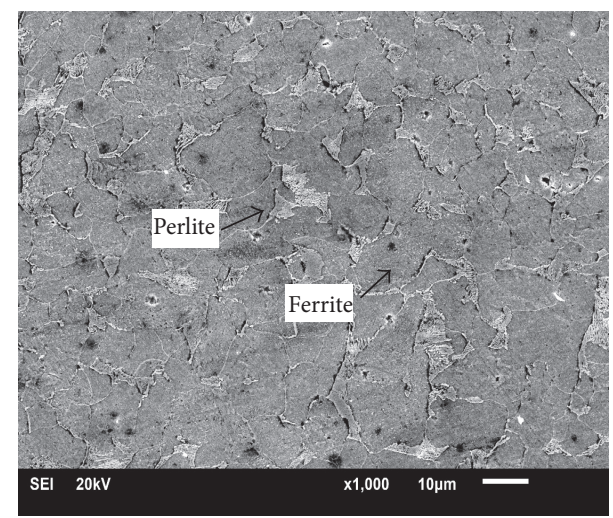

(b)

FIGURE 6: SEM microstructure in the HAZ. (a) Material after welding with the following parameters: current of 280 amperes, voltage of 28 volts, and travel speed of $11 \mathrm{~mm} / \mathrm{sec}$. (b) Material after welding with the following parameters: current of 270 amperes, voltage of 33 volts, and travel speed of $10 \mathrm{~mm} / \mathrm{sec}$.

\section{Acknowledgments}

This work was financially supported by the National Research Council of Thailand in 2016. The authors gratefully acknowledge the Department of Production Technology Education, the Faculty of Industrial Education and Technology, King Mongkut's University of Technology Thonburi (KMUTT) for contributions to this research.

\section{References}

[1] American Welding Society, Welding Handbook, vol. 4, American Welding Society, Miami, Fla, USA, 7th edition, 1982.

[2] H. Granjon, Fundamentals of Welding Metallurgy, Abington Publishing, Cambridge, UK, 1991.

[3] American Welding Society, Welding Handbook, vol. 2, American Welding Society, Miami, Fla, USA, 8th edition, 1992.

[4] X. Li, Z. Yang, Y. Chu, and J. Cheng, "The influence of electrochemical reactions induced by an external circuit on submerged arc weld metal," Materials Letters, vol. 122, pp. 5-8, 2014.
[5] D. C. Montgomery, Design and Analysis of Experiments, John Wiley \& Sons, New York, NY, USA, 5th edition, 2007.

[6] A. P. Mohsen, S. Mehrdad, and S. Morteza, "Weldability of ferritic ductile cast iron using full factorial Design of experiment," Journal of Iron and Steel Research, vol. 21, no. 2, pp. 252-263, 2014.

[7] H. Jafari, M. H. Idris, and A. Shayganpour, "Evaluation of significant manufacturing parameters in lost foam casting of thinwall $\mathrm{Al}-\mathrm{Si}-\mathrm{Cu}$ alloy using full factorial design of experiment," Transactions of Nonferrous Metals Society of China, vol. 23, no. 10, pp. 2843-2851, 2013.

[8] American Society of Mechanical Engineers, ASME Boiler and Pressure Vessel Code Section IX, American Society of Mechanical Engineers, New York, NY, USA, 2007.

[9] American Society for Metal, ASM Handbook Metallography and Microstructures, vol. 9, American Society for Metal, 1985.

[10] C. R. Hicks, Fundamental Concepts in the Design of Experiments, Rinehart and Winston: Saunders College, Holt, Calif, USA, 4th edition, 1993.

[11] D. C. Montgomery, Introduction to Statistical Quality Control, John Wiley and Son Publishing, New York, NY, USA, 1997.

[12] G. L. Zhi, G. Z. Hui, M. Qing, G. W. Zhen, and G. F. Wan, "Effect of cyclic annealing on microstructure and mechanical 
properties of medium carbon steel," Journal of Iron and Steel Research, International, vol. 23, no. 2, pp. 145-150, 2016.

[13] J. I. Barraza-Fierro, B. Campillo-Illanes, X. Li, and H. Castaneda, "Steel microstructure effect on mechanical properties and corrosion behavior of high strength low carbon steel," Metallurgical and Materials Transactions A, vol. 45, no. 9, pp. 3981-3994, 2014.

[14] B. Arivazhagan, P. Ranganath, S. K. Albert, M. Kamaraj, and S. Sundaresan, "Microstructure and mechanical properties of 9Cr-1Mo steel weld fusion zones as a function of weld metal," Composition Journal of Materials Engineering and Performance, vol. 18, no. 8, pp. 999-1004, 2009.

[15] S. Luo and S. Wu, "Effect of dynamic strain aging on the microstructure and mechanical properties of a reactor pressure vessel steel," Materials Science and Engineering A, vol. 596, pp. 25-31, 2014.

[16] W. Hui, Y. Zhang, X. Zhao, N. Xiao, and F. Hu, "High cycle fatigue behavior of V-microalloyed medium carbon steels: a comparison between bainitic and ferritic-pearlitic microstructures," International Journal of Fatigue, vol. 91, pp. 232-241, 2016.

[17] X. Bai, S. Wu, and P. K. Liaw, "Influence of thermo-mechanical embrittlement processing on microstructure and mechanical behavior of a pressure vessel steel," Materials and Design, vol. 89, pp. 759-769, 2016.

[18] P. Peasura, "Application of response surface methodology for modeling of post weld heat treatment process in a pressure vessel steel ASTM A516 grade 70," The Scientific World Journal, vol. 2015, Article ID 318475, 8 pages, 2015.

[19] R. Oyyaravelu, P. Kuppan, and N. Arivazhagan, "Metallurgical and mechanical properties of laser welded high strength low alloy steel," Journal of Advanced Research, vol. 7, no. 3, pp. 463472, 2016.

[20] N. A. C. Lah, A. Ali, N. Ismail, L. P. Chai, and A. A. Mohamed, "The effect of controlled shot peening on fusion welded joints," Materials \& Design, vol. 31, no. 1, pp. 312-324, 2010. 


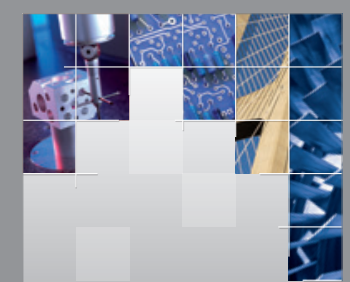

\section{Enfincering}
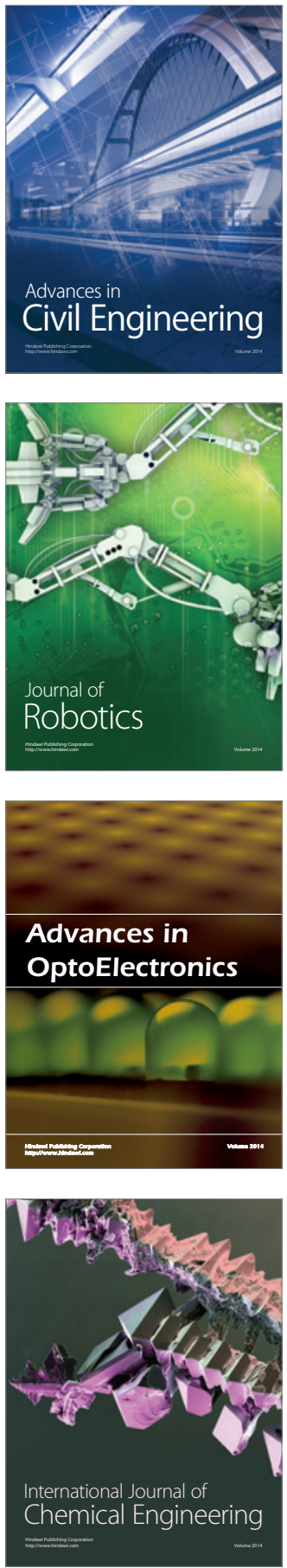

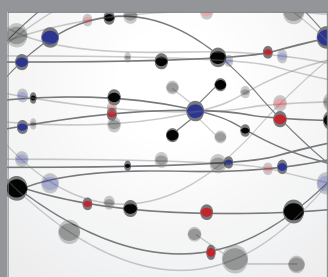

The Scientific World Journal

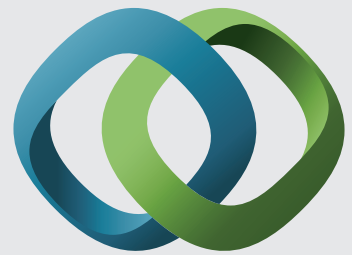

\section{Hindawi}

Submit your manuscripts at

https://www.hindawi.com
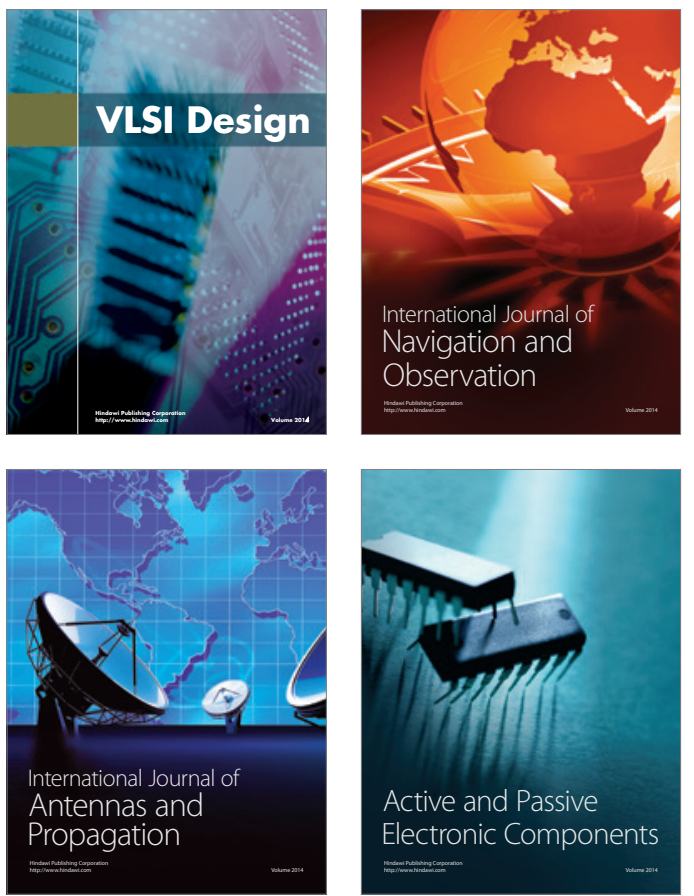
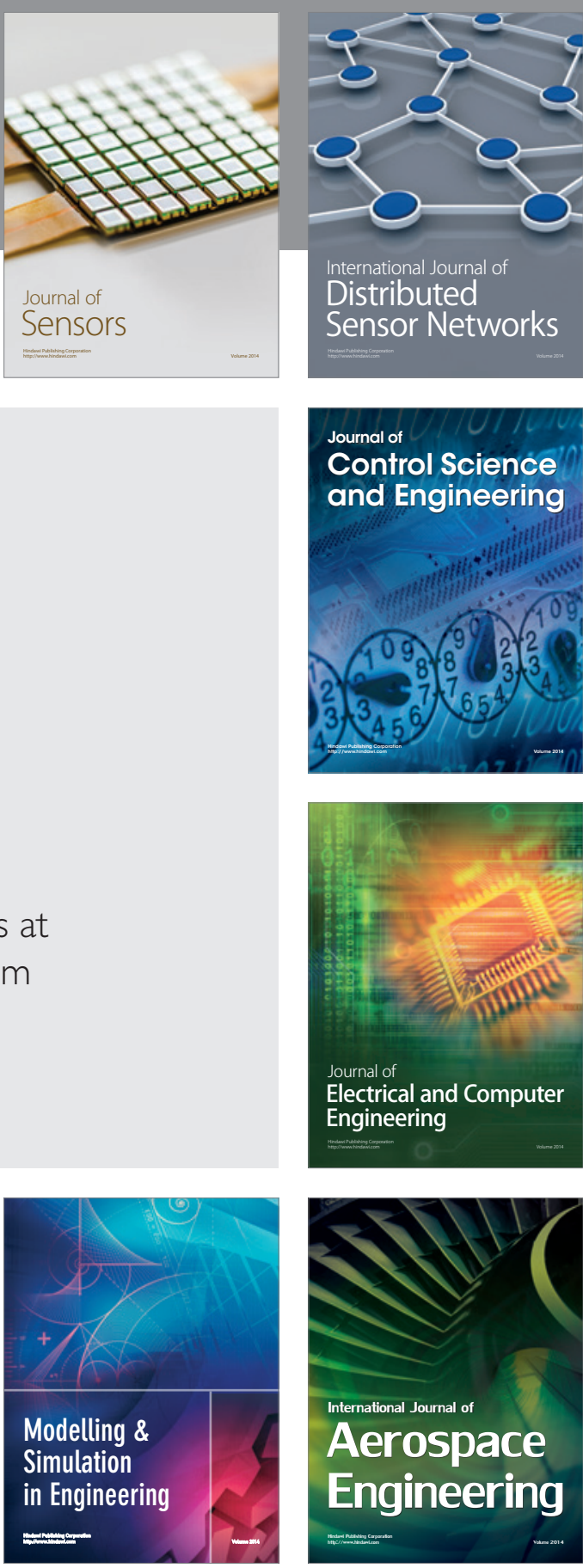

International Journal of

Distributed

Sensor Networks

$-$

Joumal of

Control Science

and Engineering
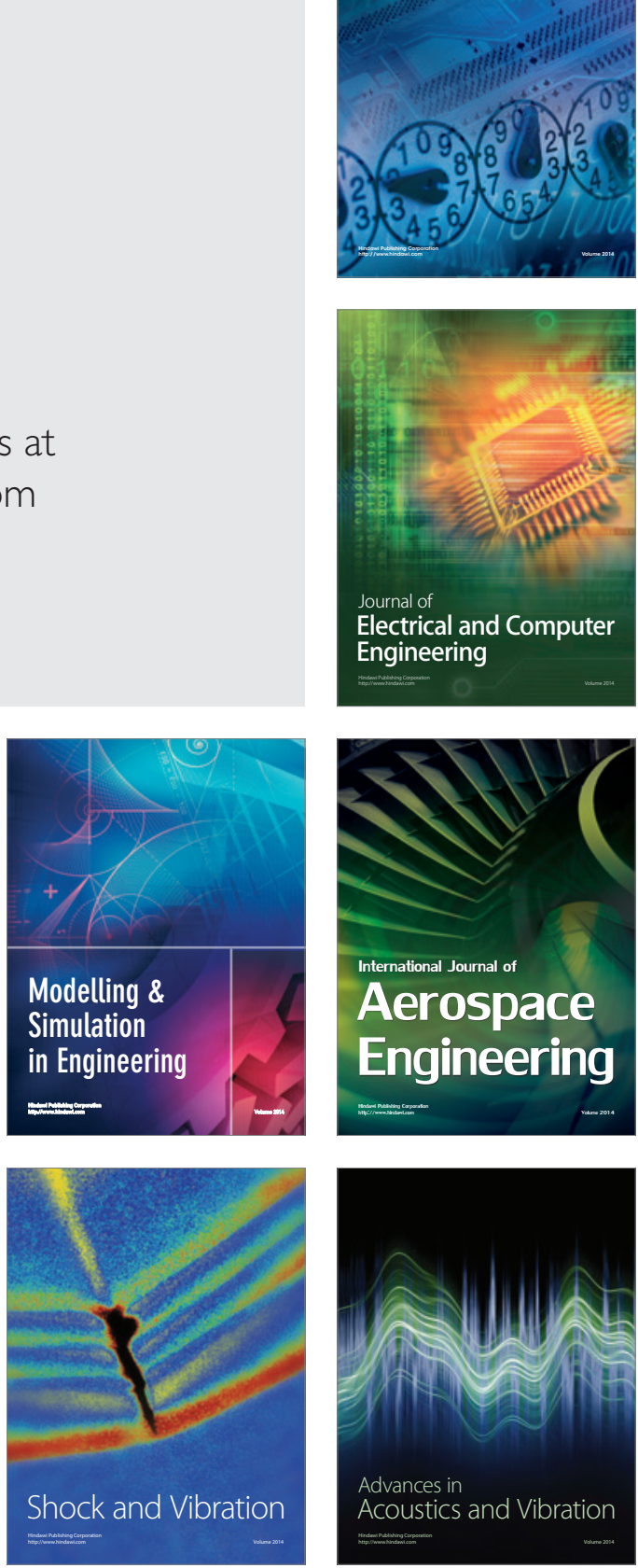